\title{
Urban Road Sections Travel Time Estimation Based on Real-time Traffic Information
}

\author{
$\mathrm{Tu} \mathrm{Xu}$ \\ School of Information Science and Technology \\ Southwest Jiaotong University \\ Chengdu 610031, China \\ yian888@163.com
}

\author{
Changlin Wang \\ School of Information Science and Technology \\ Southwest Jiaotong University, \\ Chengdu 610031, China \\ clwang@home.swjtu.edu.cn
}

\begin{abstract}
Urban transportation dynamic guidance system's foundation is estimation accurately of the road section travel time. At present exists the method needs to carry on the model to the complex transportation system or is only is suitable under specific traffic conditions, causes the travel time estimation not exactly. Introduces SVR in the road section travel time estimation, proposed the road section travel time estimate's feature vectors, had considered the traffic light to travel time's influence, and the identical road section travel time according to the direct moving, left-turn, right-turn are estimated respectively, then raises the estimate rate of accuracy. The experiment results indicated that with certain sampling interval, estimate the urban road 4 kind of road section travel times, the relative error is smaller than $10 \%$, can construct the urban transportation dynamic guidance system's necessity satisfied.
\end{abstract}

Keywords-Intelligence transportation system, Dynamic guidance system, Road section travel time estimate, Support vector regression

\section{INTRODUCTION}

According to the current real-time traffic flow information, the urban transportation dynamic guidance system can plan a shortest running time route for a driver, not only can alleviate the transportation jam, enhances the road safety, reduces the environmental pollution, reduces the energy consumption, but also can increase the existing road traveling capability, realizes the municipal transportation load balance automatically. A premise of establishing the dynamic guidance system is carries on the accurate estimate to the road section real-time travel time, and it is also important research content of the intelligence transportation system. At present, there are already several typical methods to estimate the urban road section travel time, like time series method [1, 2], Calman filtering [3], queuing theory estimate law [4], historical tendency forecast law [5], least squares method [6], similar law [7] and so on. These methods either needs to build accurate model to the transportation system, or only to some specific transportation condition under effective, and or had ignore the influence of the traffic lights. Therefore, when estimates the urban road travel time, there is big error even is not suitable.

The urban road transportation system is a time-variable, nonlinear, the non-steady complicated system, and it's very difficult to build its math model [8]. The neural network can carry on the travel time estimate without modeling to the transportation system $[9,10]$, therefore, it provided a new method to estimate the travel time. However, as a learning machine, neural network has some inherent shortages, such as "over study", local minimum, dimension disaster and so on [12]. A new learning machine, support vector machines, can overcome these questions. Yao et al. introduced support vector machine to road section travel time estimate, and makes certain progress [11]. But in Yao's research, considers only the road section travel time between road intersections, but has neglected the road intersection signal light to the road section traveling time influence, also has not considered the travel time difference between vehicles direct moving, left turn and right turn.

The research indicated that the traffic light will have the major influence on the urban road section travel time, and the travel time isn't same among vehicles direct moving, left turn and right turn even at the identical road section. This article will introduce the support vector regression machine (SVR), and considers the above factors, carries on the estimation to the urban road section travel time, thus provides the basis for the dynamic guidance system.

\section{Support Vector Machine}

Support vector machine (SVM) is a machine learning algorithm based on the statistics learning theory (SLT), take the structure risk minimum as the optimized condition, can overcome "over study", local minimum, dimension disaster, suits carries on to the small scale training sample studies [12].

SVR is a SVM branch, used in the function regression analysis. Standard SVR is called $\varepsilon$-SVR, because its expression includes the Epsilon insensitive loss function. Mathematics description of $\varepsilon$-SVR is described as follows.

Let the training sample set including 1 samples be:

$\{(\mathrm{x} 1, \mathrm{y} 1),(\mathrm{x} 2, \mathrm{y} 2), \ldots(\mathrm{x} 1, \mathrm{yl})\} \subset \mathrm{Rn} \times \mathrm{R}$

A nonlinear mapping $\Phi$ maps the training sample $\mathrm{x}$ to a high dimension feature space, where these samples may carry on the linear regression. Let the regression function be:

$$
f(x)=\langle w, \phi(x)\rangle+b
$$

Here $\mathrm{w}$ is the weight vector, $\mathrm{b}$ is a bias.

Considering the Epsilon insensitive loss function, and introducing slack variable $\xi \mathrm{i}$ and regularization parameter $\mathrm{C}$, the regression analysis primitive optimization function is: 


$$
\begin{array}{ll} 
& \min \frac{1}{2}\|w\|^{2}+C \sum_{i=1}^{l} \xi_{i} \\
\text { s.t. } & \left|f\left(x_{i}\right)-y_{i}\right| \leq \xi_{i}+\varepsilon, i=1,2, \ldots, l \\
& \xi_{i} \geq 0, i=1,2, \ldots, l
\end{array}
$$

Chooses the appropriate kernel function $k\left(x, x^{\prime}\right)$, make $k\left(x_{i}, x_{j}\right)=\left\langle\phi\left(x_{i}\right), \phi\left(x_{j}\right)\right\rangle$, the Wolfe dual question is:

$$
\begin{aligned}
& \min _{\alpha^{(2)} \in R^{2 l}} \frac{1}{2} \sum_{i=1}^{l} \sum_{j=1}^{l}\left(\alpha_{i}^{*}-\alpha_{i}\right)\left(\alpha_{j}^{*}-\alpha_{j}\right) k\left(x_{i}, x_{j}\right) \\
& +\varepsilon \sum_{i=1}^{l}\left(\alpha_{i}^{*}+\alpha_{i}\right)-\sum_{i=1}^{l} y_{i}\left(\alpha_{i}^{*}-\alpha_{i}\right) \\
& \text { s.t. } \quad \sum_{i=1}^{l}\left(\alpha_{i}-\alpha_{i}^{*}\right)=0 \\
& \quad 0 \leq \alpha_{i}, \alpha_{i}^{*} \leq \frac{C}{l}, i=1,2, \ldots, l
\end{aligned}
$$

Obtains the optimal solution:

$$
\bar{\alpha}=\left(\bar{\alpha}_{1}, \bar{\alpha}_{1}^{*}, \ldots, \bar{\alpha}_{i}, \bar{\alpha}_{i}^{*}, \ldots, \bar{\alpha}_{l}, \bar{\alpha}_{l}^{*}\right)^{T} \text {. }
$$

Then the regression estimate function is:

$$
f(x)=\sum_{i=1}^{l}\left(\bar{\alpha}_{i}^{*}-\bar{\alpha}_{i}\right) k\left(x_{i}, x\right)+\bar{b}
$$

Thus obtains the results.

\section{TRAFFIC EXAMINATION BASED ON COIL}

In the vehicles guidance system, the urban road network often is abstracted to a chart, the intersection is the node, the road section is the arc, and the road section length is weight [13].

The way that examines the volume of traffic by the coil buried under the road surface already is widespread used and has low price. Therefore, to favor realizes, this article has used based on the coil volume of traffic examination, and carried on the road section travel time estimate from this.

According to People's Republic of China profession standard CJJ37-90 "Urban road Design Standard", the urban road rank divides into four kinds:

\section{A. Expressway}

In the urban road is equipped with the medial strip, has four above automobile lanes, with three-dimensional crossing and the in/out control completely, for automobile by high speed travel path. Also calls the automobile special-purpose road. Expressway's design running speed is $60-80 \mathrm{~km} / \mathrm{h}$.

\section{B. Main route}

Connects urban various districts, its main function is traffic. The main route's design running speed is $40-60 \mathrm{~km} / \mathrm{h}$.

\section{Inferior main route}

Undertakes the transportation collection and distribution function among the main routes and various districts, at the same time, has the service function. The inferior main route's design running speed is $40 \mathrm{~km} / \mathrm{h}$.

\section{D. $\operatorname{Leg}$}

Inferior main route and neighbor road ties, service function primarily. Leg's design running speed is $30 \mathrm{~km} / \mathrm{h}$.

Regarding expressway uses the three-dimensional intersection generally, when a vehicle makes a turn, it enters the auxiliary lane firstly, exits again expressway, does not suppose the traffic light, and does not suppose the bike path. Examination coils are installed in the traffic lane entrance, between 2 detectors is a road section. When a road section is too long, may in the middle addition detector, a long road section divide into certain short road sections, causes each road section the length about $1 \mathrm{~km} \sim 3 \mathrm{~km}$, the road section whose length is lower than $1 \mathrm{~km}$ is no longer to decompose. The installment positions of coils are shown as in Figure 1. In the chart the above 4 traffic lanes are the main road, below are the auxiliary lanes, the yellow arrow is the direction of travel, the red line is examining coil.

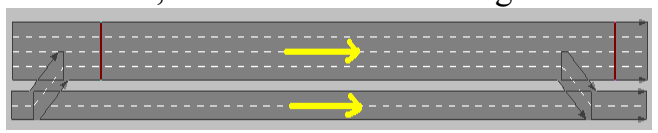

Figure 1. The Position of the Expressway Examination Coil

On the main route, the inferior main route, the leg, the node is the plane intersection generally, is controlled by signal light generally. To estimate the accuracy, the identical road section travel time are divided into the direct moving, left turn, right turn 3 kind of situations to estimate separately, the coil installs in the upstream intersection road section's exit and downstream intersection various road sections, direct moving, left turn, right turn, the exit.

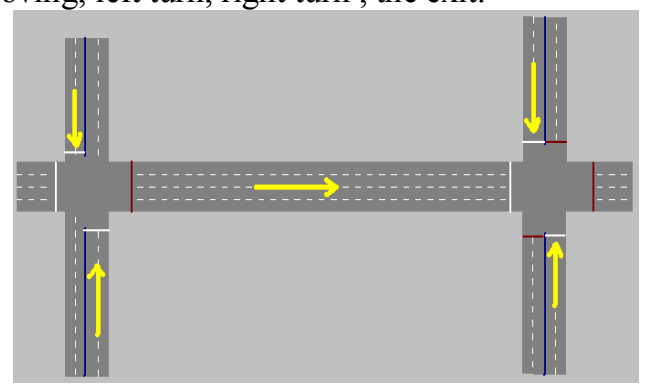

Figure 2. The Position of the Main Route Examination Coil

The main route coils install position as shown in Figure 2, white line for parking line. The inferior main route and leg's have a similar coil installing position, only the respective traffic lane number is different.

\section{ANALYSIS ABOUT THE URBAN TRAFFIC FLOW AND THE FEATURE VECTOR EXTRACTION}

If the rank of urban road is different, its traffic flow organization characteristic is not same.

\section{A. Expressway}

Expressway that connects urban each primary area is fast channel, generally composed of 4 traffic lanes. Its characteristic is the entire seal, the entire three-dimensional 
intersection, without traffic light. The volume of traffic is big, without the bike path, the flow of traffic is influenced hardly. The function relation between the stream of vehicles average velocity and the volume of traffic is quite stable. Therefore, estimation of expressway's travel time is relatively easy.

Third Ring Road of Chengdu belongs to expressway. Sample the traffic flow with fixed frequency, and carries on the actual movement test by the testing car, we find the road section travel time is related with the following factors about expressway:(1)Road section length;(2)Traffic lane quantity; (3) In previous road section and previous time interval volume of traffic;(4)Previous road section this time interval volume of traffic; (5) In this road section previous time interval volume of traffic; (6) This road section this time interval volume of traffic;(7)In this road section previous time interval average travel time. Therefore, may take the 7 dimensions feature vectors of expressway.

\section{B. Main route}

Because there is not the traffic light on expressway, traffic flow to be possible the continuous running, the saturated traffic capability is big. But on the main route, the situation completely was different. The main route is 4 traffic lanes, in addition is equipped with the bike path, with isolation fence between the bike path and the driveway. Generally intersection is plane, establishing the traffic light. Controlled by traffic light, the stream of vehicles is broken, cannot continuous running, in the same time interval, the stream of vehicles average velocity shows the very big unevenness. As a result, the functional relation between the stream of vehicles average velocity and the volume of traffic no longer maintains stable. By now, as a result of the stream of vehicles by the traffic light periodicity interruption, the difficulty which estimates the travel time of main route was increased. Moreover, as hindrance of traffic light, various directions traffic quantities of upstream intersection have not too big influence to the downstream intersection. For increasing estimation rate of accuracy, to the identical road section, estimates the travel time separately according to the stream of vehicles direct moving, left turn, and right turn.

The Second Ring Road of Chengdu belongs to the main route. After observing and analyzing on the spot, we discovers the main route travel time is relative with the following factors: (1) Road section length; (2) Traffic lane quantity;(3)This time interval volume of traffic;(4)Previous time interval volume of traffic;(5) Previous time interval average travel time;6)This road section this direction traffic light split green ratio; (7)Cycle of traffic light. Above these 7 factors can become the feather vectors of the main route.

C. Inferior main route and Leg

The inferior main route has 2 traffic lanes, there is not isolation fence between the bike path and the driveway, the bicycle stream may affect vehicles stream. Generally, the inferior main route and the main route form intersection, the traffic flow volume of inferior main route is relatively small, the traffic light has big influence to the stream of vehicles. The inferior with has smaller split green ratio than the main route at intersection. Jiaoda Road of Chengdu belongs to the inferior main route.

The leg is the channel between the urban housing estates. There is not isolation fence between the bicycle path and the driveway, lots of bicycles and pedestrians in the leg road influence the traffic flow very much, causes the effective lane to become only one.

The leg road has same feature vectors with the inferior main.

\section{EXPERIMENTAL RESULT}

To estimate the travel time, vissim 3.7, a microcosmic traffic simulation software, is used to simulate urban roads. 4 kind of urban roads are simulated in vissim respectively, and lets vissim record vehicles' average travel time, which is used to appraise the SVR study effect. Carries on the study and the travel time using Libsvm2.9 to the sample estimated that has used the Gauss nuclear function.

A. Expressway

Take the Chengdu Third Ring Road as the prototype, has established 3 expressway models with 4 traffic lanes, the road section length respectively is $1 \mathrm{~km}, 1.8 \mathrm{~km}, 2.6 \mathrm{~km}$, the vehicles turning proportion counts under Chengdu Third Ring Road Jiaotong University Three-dimension Crossing Bridge. For simulation volume of traffic from small to big, the volume of traffic respectively takes $1000 \mathrm{veh} / \mathrm{h}$, $3000 \mathrm{veh} / \mathrm{h}, 6000 \mathrm{veh} / \mathrm{h}$, and $10000 \mathrm{veh} / \mathrm{h}$. The sampling interval is $3 \mathrm{~min}$. For the guarantee data validity, starts to gather the data after the simulation starts 1 minute. Altogether 4 groups of data, each group of data includes 300 training samples, 210 test samples, altogether 1200 training samples, 840 test samples. Chooses the SVR parameter $\gamma=0.00003, \mathrm{C}=300, \varepsilon=0.001, \mathrm{e}=0.01$, carries on the training to SVR, after the test, the biggest relative error is 0.06156 , the average relative error is 0.009244 . Obviously, SVR can estimate accurately the section travel time of the expressway.

\section{B. Main route}

Take the section from Yingmengkou Three-dimension Crossing Bridge to Jiulidi Entrance on the Second Ring Road of Chengdu as the prototype, establishes 3 models to the main route with 4 traffic lanes, the length respectively is $200 \mathrm{~m}, 600 \mathrm{~m}$, and $1000 \mathrm{~m}$. The vehicles turning proportion obtains at Second Ring Road Jiaotong University Entrance, the volume of traffic takes $500 \mathrm{veh} / \mathrm{h}, 1000 \mathrm{veh} / \mathrm{h}$, and $1500 \mathrm{veh} / \mathrm{h}$ separately. Because main route is influenced seriously by traffic light, sampling interval is set to be 10 minutes for getting stable traveling time. The vehicles stream travel time of direct moving, left-turn, and right-turn are estimated separately. The traffic light uses 4 phase signal including the left-turn phase, the cycle is 240s. Takes 3 kind of split green ratio schemes to compare, under 3 kind of volume of traffic, each direction takes 9 groups of samples, each group of samples gather 303 training samples, 243 test samples. Altogether 2727 training samples and 2187 test samples are sampled.

Literature [14] proposed the algorithm that estimate travel time of the road section controlled by the traffic light with the statistical method, here has compared the estimation 
results between this method and SVR, its comparison result as shown in Table 1. Is obvious by the table, this article

\section{Inferior main route and Leg}

The traffic lane number of inferior main route is 2 , and leg's traffic lane number is 1 . Because the volume of traffic and the cycle of traffic light are both smaller than the main route, travel time of inferior main route is smoother than the main route, so the sampling interval takes 5 minutes, both distance takes $200 \mathrm{~m}, 600 \mathrm{~m}$, and $1000 \mathrm{~m}$ respectively. Jiaoda Road of Chengdu belongs to the inferior main route, but Qunxing Road belongs to the leg. The traffic light has 2 phases, with cycle 160s, takes 2 kinds of split green ratio schemes, the volume of traffic takes $500 \mathrm{veh} / \mathrm{h}, 1000 \mathrm{veh} / \mathrm{h}, 1500 \mathrm{veh} / \mathrm{h}$ separately, obtains 6 groups of data, each group of data includes 303 training samples, 243 test samples, total 1818 training samples and 1458 test samples. Train SVR and estimate the travel time, compare the relative error result with the literature [14] method, results as Table 2 and Table 3 shows. The average relative error obviously is smaller than the estimate result of statistical method.

\section{SUMMARIES}

Estimating the urban road section travel time is the foundation that establishes the municipal transportation dynamic guidance system. The existing method either needs to build the transportation system model, either only can estimate the travel time under specific traffic conditions. Here we use SVR to estimate the road section travel time, avoided to build the model of transportation system, which is a difficult problem, and had considered the influence of the traffic light to the stream of vehicles. Road section travel time is estimated according to the direct moving, left-turn, and right-turn, separately. In vissim, the transportation simulation software, simulation experiment has been done to estimate the travel time with SVR. The experiment had indicated that to all path type, the average relative error with SVR was smaller than $10 \%$, surpassed the present existence some methods, to establish the foundation of urban dynamic guidance system.

\section{ACKNOWLEDGMENT}

The research was Supported by Central University Basic Scientific Research Operation Cost Special Fund (SWJTU09BR113). method average relative error is much smaller than the literature [14] statistical method.

\section{REFERENCES}

[1] Dailey D.J. Travel time estimation using cross-correlation techniques. Transpotation Research.1993, 27B(2):97 - 107.

[2] John Rice and Erik van Zwet.A Simple and Effective Method for Prediction Travel Times on Freeways[R].the Department of Statistics of the University of California at Berkeley,2002

[3] Ramjattan A.N.and P.A.Cross.A Kalman Filter Model for An Integrated Land Vehicle Navigation System. Journal of Navigation, Vol.48, No.2, May, 1995. PP.293 - 302

[4] Nam Do.H.and Drew Donald R. Method for Estimation Freeway Travel Time in Real Time from Flow Measurements[J].Journal of Transportation Engineering,1996:185-191

[5] Chien S I, Kuchipudi C M. Dynamic t ravel time prediction wit h real2time and historic data[J]. Journal of Transportation Engineering, $2003,129(6): 6082616$

[6] YANG Shao-hui, WANG Dian-hai, WANG Ying-ping, DONG Bin. Fitting Travel Time by Least Square Method[J]. JOURNAL OF HIGHWAY AND TRANSPORTATION RESEARCH AND DEVELOPMENT. 2006, 23(9): 90-93

[7] HE Zhao-cheng ZHAO Jian-ming WANG Zhen-bo WEI Qing-bo. Travel time estimation method in urban road network with signal control. 2008, 8(4): 95-98

[8] GAO Zi-you, ZHAO Xiao-mei, HUANG Hai-jun, MAO Bao-hua. Research on Problems Related to Complex Networks and Urban Traffic Systems. JOURNAL OF TRANSPORTATION SYSTEMS ENGINEERING AND INFORMATION TECHNOLOGY. 2006 6(3): 79-84

[9] Dharia A , Adeli H. Neural network model for rapid forecasting of freeway link travel time[J]. Engineering Applications of Artificial Intelligence, 2003,16(7/8) : 607-613

[10] CHU Lian-yu YANG Zhao-sheng. Real-time Link Travel Time Estimation Based on Fuzzy Neural Network. 2000, 20(11), 111-116

[11] YAO Zhi-sheng SHAO Chun-fu XIONG Zhi-hua. Research on Use of Support Vector Machine for Forecasting Link Travel Time. JOURNAL OF HIGHWAY AND TRANSPORTATION RESEARCH AND DEVELOPMENT. 2007.24(9). 96-99

[12] Deng Nai-yang, TIAN Ying-jie. A new new method In data miningSupport Vector Machine[M]. Bei Jing: Scientific Publishing house, 2004

[13] Wang Fen. The Dijkstra most short-path optimizes the algorithm and realizes in the automobile guidance research [D]. Shanghai Normal University master paper, 2006

[14] Zhang He-sheng Zhang Yi Hu Dong-cheng . Estimation method of average travel time for road sections. JOURNAL OF TRAFFIC AND TRANSPORTATION ENGINEERING. 2008, 8(1): 89-96

Table I. This Article Method Main Route Travel Time Estimated That the Result and the Statistical Method Estimated the Result

\begin{tabular}{|c|c|c|c|c|c|c|}
\hline \multicolumn{7}{|c|}{ COMPARES } \\
\hline \multirow[b]{2}{*}{ Direction } & \multirow[b]{2}{*}{ Split green ratio } & \multicolumn{3}{|c|}{ SVR } & \multicolumn{2}{|c|}{ Statistical method } \\
\hline & & SVR parameters & $\begin{array}{c}\text { Max } \\
\text { relative } \\
\text { error }\end{array}$ & $\begin{array}{c}\text { Average } \\
\text { relative } \\
\text { error }\end{array}$ & $\begin{array}{c}\text { Max } \\
\text { relative } \\
\text { error }\end{array}$ & $\begin{array}{c}\text { Average } \\
\text { relative } \\
\text { error }\end{array}$ \\
\hline $\begin{array}{l}\text { Direct } \\
\text { moving }\end{array}$ & $0.25 / 0.4 / 0.6$ & $\mathrm{r}=0.000049 ; \mathrm{c}=9000 ; \varepsilon=0.01 ; \mathrm{e}=0.01$ & 1.008 & 0.0875 & 1.7093 & 0.3550 \\
\hline Left-turn & $0.25 / 0.1833 / 0.1333$ & $\mathrm{r}=0.000002 ; \mathrm{c}=300 ; \varepsilon=0.001 ; \mathrm{e}=0.001$ & 0.957 & 0.0953 & 0.9449 & 0.5745 \\
\hline Right-turn & $0.25 / 0.4 / 0.6$ & $\mathrm{r}=0.0003 ; \mathrm{c}=70 ; \varepsilon=0.01 ; \mathrm{e}=0.01$ & 2.6689 & 0.0998 & 5.8640 & 0.3595 \\
\hline
\end{tabular}


Table II. This Article Method Inferior Main Route Travel Time Estimated That the Result and the Statistical Method Estimated the RESULT COMPARES

\begin{tabular}{|c|c|c|c|c|c|c|}
\hline \multirow[b]{2}{*}{ Direction } & \multirow[b]{2}{*}{ Split green ratio } & \multicolumn{3}{|c|}{ SVR } & \multicolumn{2}{|c|}{ Statistical method } \\
\hline & & SVR parameters & $\begin{array}{c}\text { Max } \\
\text { relative } \\
\text { error }\end{array}$ & $\begin{array}{c}\text { Average } \\
\text { relative error }\end{array}$ & $\begin{array}{c}\text { Max } \\
\text { relative } \\
\text { error }\end{array}$ & $\begin{array}{l}\text { Average } \\
\text { relative error }\end{array}$ \\
\hline $\begin{array}{c}\text { Direct } \\
\text { moving }\end{array}$ & $0.4375 / 0.7375$ & $\mathrm{r}=0.0002 ; \mathrm{c}=1000 ; \varepsilon=0.01 ; \mathrm{e}=0.01$ & 0.6027 & 0.05874 & 4.0795 & 0.3676 \\
\hline Left-turn & $0.4375 / 0.7375$ & $\mathrm{r}=0.0002 ; \mathrm{c}=400 ; \varepsilon=0.01 ; \mathrm{e}=0.01$ & 0.6948 & 0.08677 & 3.6828 & 0.3713 \\
\hline Right-turn & $0.4375 / 0.7375$ & $\mathrm{r}=0.0002 ; \mathrm{c}=300 ; \varepsilon=0.01 ; \mathrm{e}=0.01$ & 1.1191 & 0.09644 & 4.7579 & 0.3827 \\
\hline
\end{tabular}

TABle III. This ARticle Method Leg Travel Time Estimated That the Result and the Statistical Method Estimated the Result Compares

\begin{tabular}{|c|c|c|c|c|c|c|}
\hline \multirow[b]{2}{*}{ Direction } & \multirow[b]{2}{*}{ Split green ratio } & \multicolumn{3}{|c|}{ SVR } & \multicolumn{2}{|c|}{ Statistical method } \\
\hline & & SVR parameters & $\begin{array}{c}\text { Max } \\
\text { relative } \\
\text { error }\end{array}$ & $\begin{array}{c}\text { Average } \\
\text { relative error }\end{array}$ & $\begin{array}{c}\text { Max } \\
\text { relative } \\
\text { error }\end{array}$ & $\begin{array}{l}\text { Average } \\
\text { relative error }\end{array}$ \\
\hline $\begin{array}{l}\text { Direct } \\
\text { moving }\end{array}$ & $0.4375 / 0.7375$ & $\mathrm{r}=0.0003 ; \mathrm{c}=800 ; \varepsilon=0.01 ; \mathrm{e}=0.01$ & 0.5620 & 0.0587 & 1.4350 & 0.4970 \\
\hline Left-turn & $0.4375 / 0.7375$ & $\mathrm{r}=0.0004 ; \mathrm{c}=7000 ; \varepsilon=0.01 ; \mathrm{e}=0.01$ & 3.0133 & 0.0990 & 1.3180 & 0.5142 \\
\hline Right-turn & $0.4375 / 0.7375$ & $\mathrm{r}=0.0004 ; \mathrm{c}=4000 ; \varepsilon=0.01 ; \mathrm{e}=0.01$ & 1.0636 & 0.0922 & 1.5812 & 0.5174 \\
\hline
\end{tabular}

